\title{
Structural Characterization and Mechanical Properties of a Titanium Nitride-Based Nanolayer Prepared by Nitrogen Ion Implantation on a Titanium Alloy
}

\author{
Petr Vlcak, Josef Sepitka, Jan Drahokoupil, Tomas Horazdovsky, and Zdenek Tolde \\ Faculty of Mechanical Engineering, Czech Technical University in Prague, Technicka 4, 16607 Prague, Czech Republic \\ Correspondence should be addressed to Petr Vlcak; petr.vlcak@fs.cvut.cz
}

Received 30 August 2016; Accepted 21 November 2016

Academic Editor: Shafiul Chowdhury

Copyright (C) 2016 Petr Vlcak et al. This is an open access article distributed under the Creative Commons Attribution License, which permits unrestricted use, distribution, and reproduction in any medium, provided the original work is properly cited.

A functionalized surface nanolayer less than $200 \mathrm{~nm}$ in thickness was prepared by nitrogen ion implantation at fluences of $2 \cdot 10^{17}, 4 \cdot 10^{17}$, and $6 \cdot 10^{17} \mathrm{~cm}^{-2}$ and at an accelerating voltage of $90 \mathrm{kV}$ on the Ti6Al4V alloy. The evolution of the surface mechanical properties and the structural mechanism of the hardening were investigated. X-ray diffraction showed a great number of $\alpha \mathrm{Ti}+\mathrm{N}$ interstitial nitrogen atoms and finely dispersed TiN precipitates in the modified surface nanolayer. The functionalized surface nanolayer on the sample with applied fluence of $2 \cdot 10^{17} \mathrm{~cm}^{-2}$ had a predominant amount of $\alpha \mathrm{Ti}+\mathrm{N}$ of about $45 \mathrm{wt} \%$ with minority TiN compound up to $20 \mathrm{wt} \%$. The TiN content increased dramatically with increasing fluence of the implanted nitrogen. Nanoindentation investigations found that the indentation hardness improved up to $408 \%$ and that the reduced elastic modulus was increased up to $140 \%$. The main hardening mechanism varied with the nitrogen concentration. Nitrogen ion implantation at low fluence of $2 \cdot 10^{17} \mathrm{~cm}^{-2}$ led to a functionalized surface nanolayer in which the hardening was mainly caused by the microstrain due to the large amount of interstitially located nitrogen. Applied fluences of $4 \cdot 10^{17}$ and $6 \cdot 10^{17} \mathrm{~cm}^{-2}$ increased the content of TiN compounds, which became the predominant hardening mechanism.

\section{Introduction}

Titanium alloys are widely used in aviation, in the chemical industry, and in total joint replacements because of their low specific weight, good corrosion resistance, high toughness, high yield strength, and efficient biocompatibility [1-4]. However, titanium materials have poor wear resistance, high friction, low hardness, and poor chemical resistance in some environments $[5,6]$. The risk of allergic reactions and also possible ways to prevent allergic reactions to titanium and its alloys have come under discussion [7]. The surface properties of titanium alloys therefore often need to be modified. Several methods for modifying the surface properties can be applied, for example, plasma-enhanced chemical vapor deposition (PECVD), filtered cathode vacuum arc (FCVA), ion implantation (II), ion beam mixing (IBM), and ion beam assisted deposition (IBAD) [8-11].

Ion implantation, that is, kinetic doping of atoms into the surface area, has been shown to provide improved mechanical properties, wear resistance, and corrosion resistance in a range of materials, including metals, polymers, and ceramics. This advanced technique has several merits in comparison with other surface modification methods. For example, (1) there is high adhesion of a thin layer integrated into the surface area, (2) it is a low-temperature process, and (3) the process parameters (ion energy, fluence, and depth distribution) can be precisely controlled. Reactive elements implanted into the titanium matrix can produce a functionalized surface layer composed of metastable, amorphous, and crystalline phases, solid solutions, and crystal lattice defects. Schmidt et al. [12] and Pierret et al. [13] found that ion implantation of nitrogen and carbon into Ti-6Al-4V alloy led to reduced wear during a sliding test against UHMWPE and alumina. High wear resistance was achieved by a combination of high hardness of the implanted area and a low friction oxide or carbon film on the surface. Loinaz et al. [14] studied the influence of fluences of oxygen on the hardness and the friction coefficient of Ti6Al4V implanted with oxygen. 
TABLE 1: Elemental chemical composition of Ti6Al4V (wt\%).

\begin{tabular}{lcccccccc}
\hline Ti6Al4V & $\mathrm{C}$ & $\mathrm{O}$ & $\mathrm{N}$ & $\mathrm{H}$ & $\mathrm{Fe}$ & $\mathrm{Al}$ & $\mathrm{V}$ & $\mathrm{Ti}$ \\
\hline Range & 0,1 & 0.2 & 0.05 & 0.0125 & 0.3 & $5.50-6.75$ & $3.50-4.50$ & Balance \\
\hline
\end{tabular}

The influence of niobium implantation on the surface layer of a $\mathrm{Ti}-\mathrm{Al}-\mathrm{Zr}$ alloy and the tribological properties were investigated by $\mathrm{Zu}$ et al. [15]. A great improvement in wear resistance was observed in correlation with the decrease in the friction coefficient and the increase in hardness, as a result of the formation of niobium compounds when ion implantation with a titanium substrate was performed.

This paper reports on an experiment in which a titanium nitride-based nanolayer was prepared by nitrogen ion implantation on Ti6AAl4V alloy. The aim of this work was to examine the effect of the nitrogen concentration on phase representation in the modified surface area and the structural mechanisms of hardening. We present the relationships between the chemical composition, the phase composition, the structure, and the mechanical properties of a titanium nitride-based nanolayer.

\section{Materials and Methods}

2.1. Ion Implantation Process. The substrate material used in the study was Ti6Al4V alloy. The elemental chemical composition is shown in Table 1 . Samples $20 \mathrm{~mm}$ in diameter and $6 \mathrm{~mm}$ in thickness were cut from a bar and were then polished with 150-2500 emery paper. Final polishing was done with two steps of diamond paste $5 \mu \mathrm{m}$ and $0.5 \mu \mathrm{m}$. The samples were degreased with acetone, followed by ultrasonic cleaning in isopropyl alcohol.

The polished samples were placed onto a sample holder, and the base pressure in the vacuum chamber was $1.0 \times$ $10^{-4} \mathrm{~Pa}$. Nitrogen ion implantation was carried out at an accelerating voltage of $90 \mathrm{kV}$ at fluences of $2 \cdot 10^{17}, 4 \cdot 10^{17}$, and $6 \cdot 10^{17} \mathrm{~cm}^{-2}$. During the implantation process, the work pressure was $\sim 5 \cdot 10^{-3} \mathrm{~Pa}$, the ion beam current was $\sim 2 \mu \mathrm{A}$, and the temperature of the sample was below $80^{\circ} \mathrm{C}$.

2.2. Characterization Methods. The concentration profiles of the implanted nitrogen were measured by Rutherford backscattering spectroscopy (RBS), using a $2.1 \mathrm{MeV}$ He beam scattered at an angle of $170^{\circ}$.

The phase composition and microstructure were investigated using X-ray diffraction (XRD). A structural characterization was obtained from simulations of the X-ray curves acquired with a Panalytical X'Pert PRO instrument working in parallel beam configuration, with a Göbel mirror on the incident beam side and a parallel plate collimator on the diffracted beam side. The angle of incidence was $0.6^{\circ}$ and $1.5^{\circ}$. Measurements with the parallel beam configuration were supplemented by Bragg-Brentano geometry to obtain the whole diffraction pattern with better resolution and more quickly.

The mechanical characteristics (indentation hardness $H_{\text {IT }}$ and reduced elastic modulus $E_{r}$ ) of the modified samples

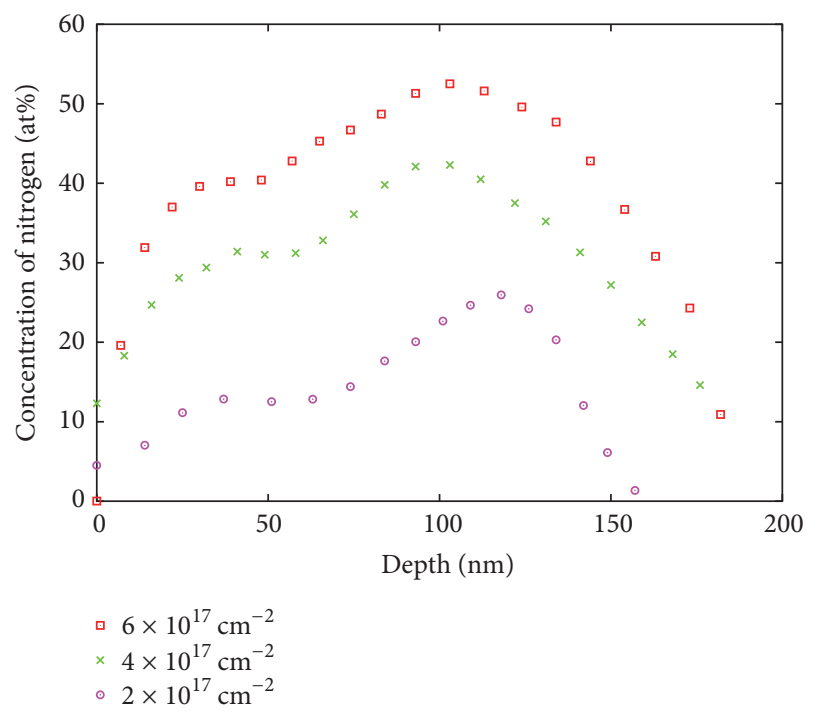

FIGURE 1: Concentration profiles of nitrogen in the implanted Ti6Al4V alloy.

were investigated by nanoindentation testing. A Triboindenter TI 950 Nanomechanical instrument (Hysitron, Inc., USA) was used. Depth profiles were investigated using the partial unloading function $\left(P_{\max }=5000 \mu \mathrm{N}, 39\right.$ cycles consisted of loading, dwell, and unloading segments, each lasting 1 second) with a Berkovich diamond tip [16]. Indents were placed on the each sample in a $3 \times 4$ matrix with $10 \mu \mathrm{m}$ separation between each indent. The nanoindentation experiment was carried out at a temperature of $22.3^{\circ} \mathrm{C}$. The Oliver and Pharr model was applied to each unloading segment of the nanoindentation function to obtain the elastic reduced modulus and the indentation hardness [17].

A field emission scanning electron microscope (SEMEDS JEOL, Japan) was used to characterize the morphology.

\section{Results and Discussion}

3.1. Concentration Profiles of Nitrogen. The concentration profiles of the implanted nitrogen atoms evaluated from the RBS measurements are shown in Figure 1. With increasing fluence, more nitrogen atoms were found in deeper layer. The maximum nitrogen ion range of $\sim 180 \mathrm{~nm}$ was found for fluence of $6 \cdot 10^{17} \mathrm{~cm}^{-2}$. The maximum concentration values of nitrogen are presented in Table 2. A comparison of the concentration profiles in Figure 1 shows that the nitrogen concentration increases with increasing fluence, the concentration profiles are asymmetric, and the peak moves closer to the surface. The observed changes in the concentration profiles are attributed to two possible factors. The first factor is the diffusion of nitrogen atoms inside the substrate (deep 
TABLE 2: Maximum nitrogen concentration and phase representation of the modified surface area of the Ti6Al4V alloy (wt\%).

\begin{tabular}{|c|c|c|c|c|}
\hline Fluence of implanted nitrogen $\left(\mathrm{cm}^{-2}\right)$ & Ref. sample & $2 \cdot 10^{17}$ & $4 \cdot 10^{17}$ & $6 \cdot 10^{17}$ \\
\hline Maximum concentration of nitrogen (at.\%) & - & 26 & 42 & 52 \\
\hline Depth (nm) & - & 118 & 103 & 103 \\
\hline$\beta$ - $\mathrm{Ti}$ & 10 & 8 & 8 & 4 \\
\hline$\alpha-\mathrm{Ti}$ & 90 & 28 & 35 & 23 \\
\hline$\alpha \mathrm{Ti}+\mathrm{N}$ & - & 45 & - & 1 \\
\hline TiN & - & 19 & 58 & 73 \\
\hline
\end{tabular}

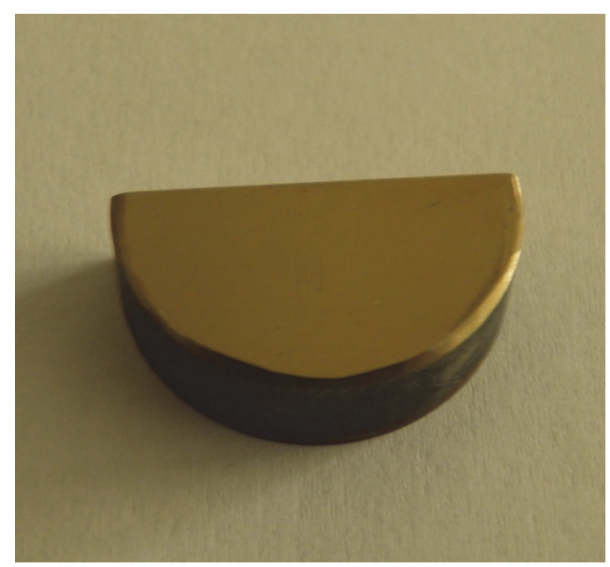

(a)

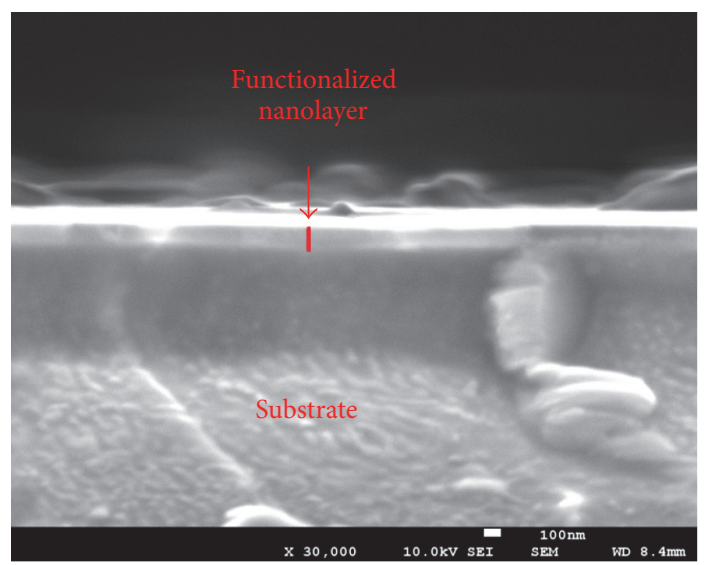

(b)

FIGURE 2: Image of a surface modified by nitrogen ion implantation with fluence of $4 \cdot 10^{17} \mathrm{~cm}^{-2}$ (a) and cross-sectional SEM images of the functionalized surface nanolayer (b).

down and towards the surface), while the second factor is sputtering of the surface during ion implantation. The radiation damage originated from nuclear collisions during implantation process intensifies the diffusion of nitrogen towards the surface (radiation enhanced diffusion). It can be seen that the effect of radiation enhanced diffusion on the shape of the concentration profile increases with the fluence of the implanted nitrogen. Some authors have reported that a elevated temperature during ion implantation can also affect the shape of the concentration profiles $[16,18]$.

\subsection{Characterization of the Modified Surface. A Ti6Al4V} surface modified by nitrogen ion implantation is shown in Figure 2. All applied fluences led to the characteristic coloration of the surface (Figure $2(\mathrm{a})$ ) and to the formation of a continuous surface nanolayer (Figure 2(b)). The bright streak observed over the modified layer is caused by the sharp edge and surface mirroring due to tilting of the sample. EDS analysis of the chemical composition confirms nitrogen enrichment in the observed nanolayer; see Figure 3.

Phase representation in the functionalized surface nanolayer was investigated by XRD. If Bragg-Brentano geometry was used, the information was dominated by the matrix, and very little information was contributed by the modified nanolayer. An exact diffraction study of the microstructure as a function of depth is complicated, due to the exponential character of the X-ray absorption in the material. However,

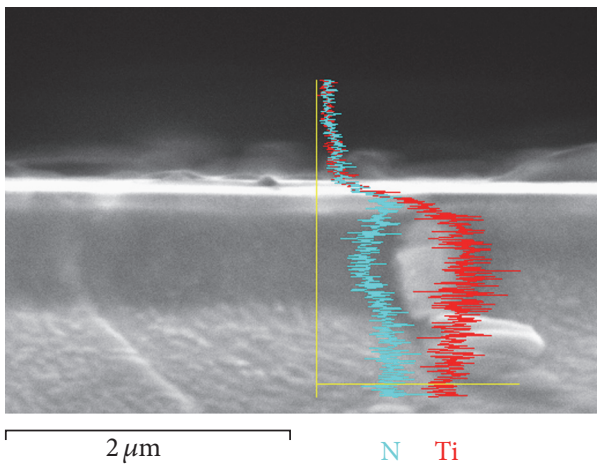

FIGURE 3: A cross-sectional SEM image of the functionalized surface nanolayer with the corresponding EDS line scan analysis of titanium and nitrogen.

an interesting view into the depth dependence can be given by changing the angle of incidence. A comparison of the diffraction patterns for various angles of incidence is presented in Figure 4 for a sample implanted with fluence of $4 \cdot 10^{17} \mathrm{~cm}^{-2}$. The incident angle varied with angle $2 \theta$ as $2 \theta / 2$ for BraggBrentano geometry. The corresponding effective depth of penetration for the plotted region varied between $2000 \mathrm{~nm}$ and $3000 \mathrm{~nm}$. The corresponding effective penetration depth for angle of incidence equal to $0.6^{\circ}$ was $70 \mathrm{~nm}$, and for angle 
TABLE 3: Values of microstrain of modified surface area of the Ti6Al4V alloy.

\begin{tabular}{lccc}
\hline Fluence of implanted nitrogen $\left(\mathrm{cm}^{-2}\right)$ & $\alpha$-Ti & $\alpha \mathrm{Ti}+\mathrm{N}$ & TiN \\
\hline Ref. sample & 0.1 & - & - \\
$2 \cdot 10^{17}$ & 0.16 & 0.60 & 0.35 \\
$4 \cdot 10^{17}$ & 0.09 & 0.47 & 0.28 \\
$6 \cdot 10^{17}$ & 0.17 & 0.43 & 0.35 \\
\hline
\end{tabular}

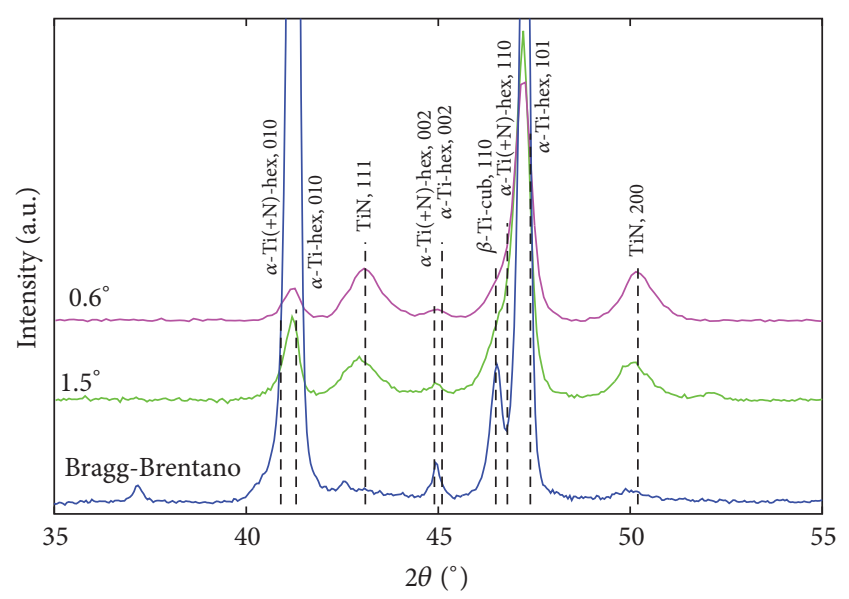

FIGURE 4: A comparison of the diffraction patterns measured at various angles of incidence on a sample implanted with fluence of $4 \cdot 10^{17} \mathrm{~cm}^{-2}$.

of incidence $1.5^{\circ}$ the effective penetration depth was $170 \mathrm{~nm}$. It is evident that the lowest angle of incidence is $0.6^{\circ}$; effective penetration depths lower than the maximum for nitrogen concentration result in distortion of the results due to low penetration of the X-rays. Even greater distortion of the results was caused by Bragg-Brentano geometry, due to the deep effective penetration depth. An effective penetration depth of $170 \mathrm{~nm}$ for an angle of incidence of $1.5^{\circ}$ was consistent with the modified surface area, as follows from the RBS concentration profiles.

Details of X-ray diffraction patterns measured with an angle of incidence of $1.5^{\circ}$ for the modified samples and for the reference sample are presented in Figure 5. XRD measurements showed that the microstructure of the initial reference sample consists of approximately $90 \mathrm{wt} \%$ of $\alpha-\mathrm{Ti}$ phase and $10 \mathrm{wt} \%$ of $\beta$-Ti phase. The samples have moderate 010 preferred orientation. The texture index (the ratio between the observed intensity and a theoretical calculation of the intensity of an untextured sample) of 010 diffraction is about 11.25. The texture index of 002 diffraction is 0.38 . The hexagonal axis is therefore preferably oriented parallel with the surface, and the basal direction is perpendicular to the surface. The XRD patterns of implanted samples show additional reflections at $2 \theta$ of about 40.8, 43.1, 44.7, 46.7, and $50.2^{\circ}$ besides the titanium peaks. These peaks can be identified as $\alpha \mathrm{Ti}+\mathrm{N}$ and $\mathrm{TiN}$. The most intense titanium reflection of the modified samples at about $47.3^{\circ}$ shows a shoulder at the low angle side. The peak shoulder is assumed to be due to titanium lattice deformation resulting from

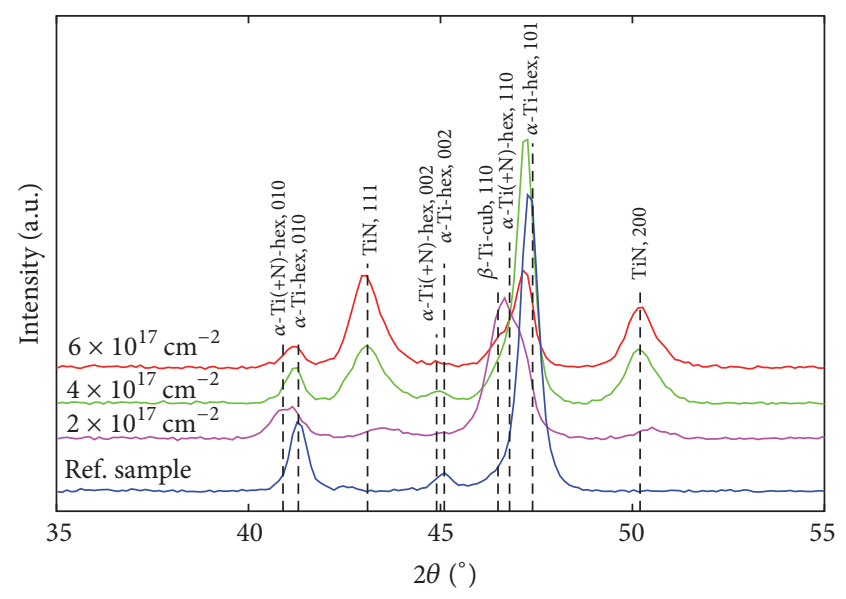

Figure 5: A detail of the X-ray diffraction patterns of the modified Ti6Al4V samples. The background has been subtracted for better visual comparison.

interstitially located atoms of implanted nitrogen. A broad peak of the sample with applied fluence of $2 \cdot 10^{17} \mathrm{~cm}^{-2}$ shifted to somewhat lower $2 \theta$ values. The observed peak broadening implies a large representation of interstitially located nitrogen in the titanium matrix $(\alpha \mathrm{Ti}+\mathrm{N})$. Significant TiN diffractions can be observed on the samples with applied fluences of $4 \cdot 10^{17}$ and $6 \cdot 10^{17} \mathrm{~cm}^{-2}$. The nitrogen concentration is above 40 at $\%$ in these samples. The high nitrogen concentration and the large amount of energy delivered by nuclear collisions led to the arrangement of the nitrogen in the structure and the predominant formation of TiN. This confirms the results of the quantitative phase analysis presented in Table 2. The functionalized surface nanolayer on the sample with applied fluence of $2 \cdot 10^{17} \mathrm{~cm}^{-2}$ has a predominant amount of $\alpha \mathrm{Ti}+\mathrm{N}$ of about $45 \mathrm{wt} \%$ with minority TiN compound up to $20 \mathrm{wt} \%$. The large amount of interstitially located nitrogen causes the largest microstrain in this nanolayer; see Table 3 . The TiN content increases dramatically with increasing fluence. The functionalized surface nanolayer on the sample with applied fluence of $4 \cdot 10^{17}$ and $6 \cdot 10^{17} \mathrm{~cm}^{-2}$ showed a predominant amount of TiN compound of above $50 \mathrm{wt} \%$. The low microstrain in these nanolayers confirms a low content of $\alpha \mathrm{Ti}+\mathrm{N}$. The results of the qualitative and quantitative phase analysis presented in this work confirm that the nitrogen ion implantation stabilized $\alpha \mathrm{Ti}$ [19] and that the nitrogen concentration has a strong influence on the phase composition of the functionalized surface nanolayer. 
TABLE 4: The maximum mechanical property values of the titanium nitride based nanolayer.

\begin{tabular}{|c|c|c|c|c|}
\hline Fluence of $\mathrm{N}$ atoms $\left(\mathrm{cm}^{-2}\right)$ & Ref. sample & $2 \cdot 10^{17}$ & $4 \cdot 10^{17}$ & $6 \cdot 10^{17}$ \\
\hline Maximum indentation hardness (GPa) & $5.3 \pm 0.5$ & $16.3 \pm 2.2$ & $19.8 \pm 2.6$ & $21.6 \pm 2.2$ \\
\hline Contact depth (nm) & $14 \pm 1$ & $17 \pm 2$ & $18 \pm 2$ & $15 \pm 2$ \\
\hline Maximum reduced elastic modulus (GPa) & $132.5 \pm 10.5$ & $155.3 \pm 11.2$ & $179.6 \pm 15.4$ & $185.2 \pm 11.5$ \\
\hline Contact depth (nm) & $24 \pm 1$ & $13 \pm 2$ & $10 \pm 1$ & $13 \pm 1$ \\
\hline
\end{tabular}

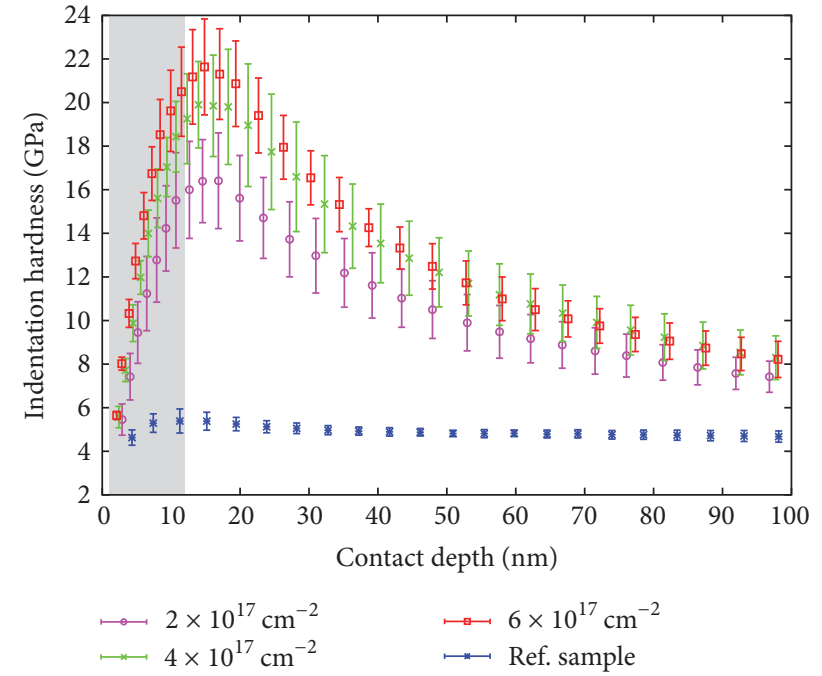

Figure 6: Indentation hardness versus contact depth for the Ti6Al4V samples modified by ion implantation. The gray oblong demarcates uncalibrated data.

3.3. Surface Mechanical Properties. The mechanical properties (indentation hardness $H_{\mathrm{IT}}$ and reduced elastic modulus $E_{r}$ ) as a function of contact depth for the reference sample and for samples implanted with nitrogen ions are shown in Figures 6 and 7. The results indicate that the mechanical properties increase with increasing fluence of the implanted nitrogen atoms. The trends (outside the uncalibrated region in Figures 6 and 7) show a decrease in mechanical properties from maximal values to the value of substrate mechanical properties with increasing contact depth. The uncalibrated region is attributed to the way the mechanical properties values were calculated at $h_{c} \rightarrow 0 \mathrm{~nm}$, using the Oliver and Pharr method $[17,20]$.

The maximum $H_{\mathrm{IT}}$ and $E_{r}$ values for each modified sample are in the ranges from $5 \%$ to $10 \%$ of the nanolayer thickness, as follows from the RBS nitrogen depth profiles in Figure 1. The measured maximum values for the mechanical properties of the titanium nitride-based nanolayer are compared in Table 4. Nitrogen ion implantation increases $H_{\text {IT }}$ to 308,374 , and $408 \%$ for fluences of $2 \cdot 10^{17}, 4 \cdot 10^{17}$, and $6 \cdot 10^{17} \mathrm{~cm}^{-2}$ and increases $E_{r}$ to 117,136 , and $140 \%$ for fluences of $2 \cdot 10^{17}, 4 \cdot 10^{17}$, and $6 \cdot 10^{17} \mathrm{~cm}^{-2}$, respectively, compared to the reference sample. The improvement in the mechanical properties is directly connected with the increasing nitrogen concentration and with microstructural changes of the functionalized surface nanolayer. It is well known that TiN compounds are hard and improve the mechanical properties

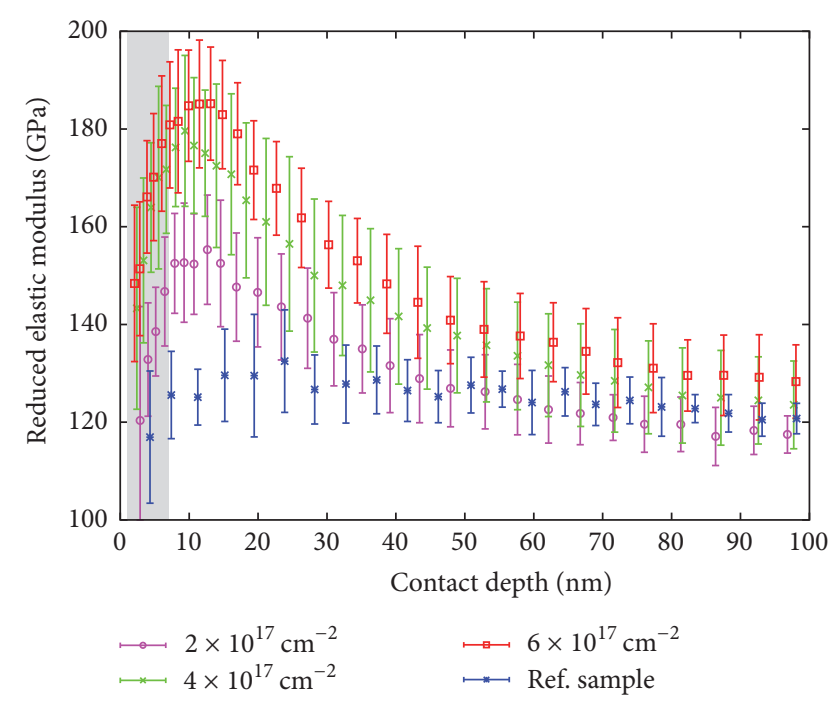

FIgURE 7: Reduced elastic modulus versus contact depth for Ti6Al4V samples modified by ion implantation. The gray oblong demarcates uncalibrated data.

$[20,21]$. The functionalized surface nanolayer formed at fluence of $2 \cdot 10^{17} \mathrm{~cm}^{-2}$ (nitrogen concentration of about 26 at\%) shows a significant increase in mechanical properties, although a low TiN content was found in the structure. The large amount of interstitially located nitrogen in the titanium matrix ( $\alpha \mathrm{Ti}+\mathrm{N}$ of about $45 \mathrm{wt} \%$ ) generates a great amount of microstrain. The great amount of microstrain due to point defects explains the hardening in this case. Higher nitrogen concentration (42 and 52 at\%) led to a predominant amount of TiN (58 and $73 \mathrm{wt} \%$ ) in the structure. The high content of TiN causes the high mechanical property values. The results show clearly that the main hardening mechanism varies with the nitrogen concentration. Nitrogen ion implantation at low fluence of $2 \cdot 10^{17} \mathrm{~cm}^{-2}$ led to the functionalized surface nanolayer, in which the hardening is caused mainly by the microstrain due to the large amount of interstitially located nitrogen. High applied fluences of $4 \cdot 10^{17}$ and $6 \cdot 10^{17} \mathrm{~cm}^{-2}$ increased the content of TiN compounds, which became the predominant hardening mechanism. However, the resulting improvement in the surface mechanical properties is caused simultaneously by the microstrain due to the point lattice defect, newly formed hard compounds, intermetallic phases, and solid solutions. The results of a comparison of the mechanical characteristics in Figure 8 shows that the reduced elastic modulus and the indentation hardness have a similar increasing trend with increasing fluence. An increase in 


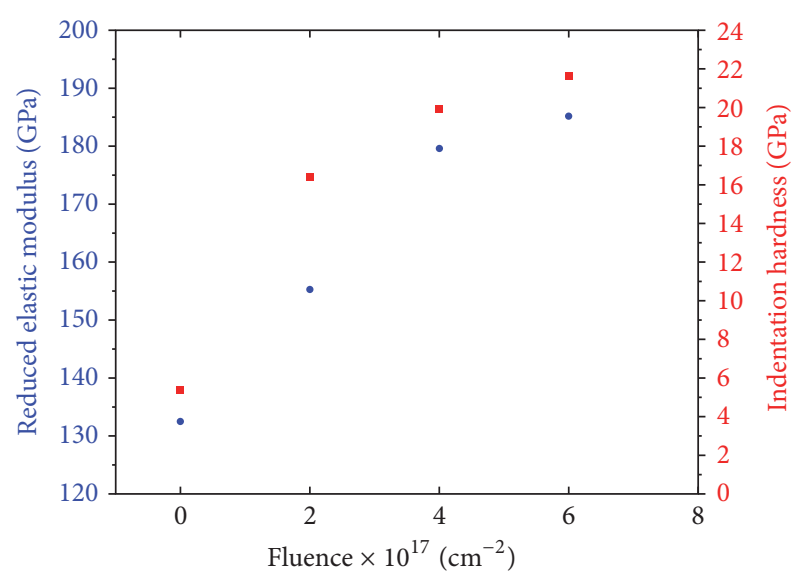

FIGURE 8: A comparison of the mechanical characteristics. Maximum reduced elastic modulus and indentation hardness versus fluence of the implanted nitrogen.

the reduced elastic modulus with the applied fluence of implanted atoms means a solid surface nanolayer with high hardness.

\section{Conclusion}

An ion implantation technique has been used for functionalizing the surface area of Ti6Al4V alloy and for irradiationenhanced hardening of the surface. The high applied fluences of the implanted nitrogen atoms caused the formation of a titanium nitride-based nanolayer integrated in the surface area. XRD analysis showed that the functionalized surface nanolayer of a sample implanted with fluence of $2 \cdot 10^{17} \mathrm{~cm}^{-2}$ contains a predominant amount of $\alpha \mathrm{Ti}+\mathrm{N}$ of about $45 \mathrm{wt} \%$ with minority TiN compound up to $20 \mathrm{wt} \%$. The TiN content was increased dramatically with increasing fluence of the implanted nitrogen. The functionalized surface nanolayer on the sample with applied fluence of $4 \cdot 10^{17}$ and $6 \cdot 10^{17} \mathrm{~cm}^{-2}$ is composed of a predominant amount of TiN compound of above $50 \mathrm{wt} \%$. Nitrogen ion implantation increased the indentation hardness by 308,374 , and $408 \%$ for fluences of $2 \cdot 10^{17}, 4 \cdot 10^{17}$, and $6 \cdot 10^{17} \mathrm{~cm}^{-2}$ and increased the reduced elastic modulus by 117,136 , and $140 \%$ for fluences of $2 \cdot 10^{17}$, $4 \cdot 10^{17}$, and $6 \cdot 10^{17} \mathrm{~cm}^{-2}$, respectively. The main hardening mechanism varied with the nitrogen concentration. Nitrogen ion implantation at low fluence of $2 \cdot 10^{17} \mathrm{~cm}^{-2}$ led to a functionalized surface nanolayer in which the hardening is caused mainly by the microstrain due to the large amount of interstitially located nitrogen. Applied fluences of 4 . $10^{17}$ and $6 \cdot 10^{17} \mathrm{~cm}^{-2}$ increased the content of TiN compounds, which became the predominant hardening mechanism.

\section{Competing Interests}

The authors declare that there is no conflict of interests regarding the publication of this paper.

\section{Acknowledgments}

This work has been supported by Research Project no. GA1622276 S of the Czech Science Foundation.

\section{References}

[1] M. Peters, J. Kumpfert, C. H. Ward, and C. Leyens, “Titanium alloys for aerospace applications," Advanced Engineering Materials, vol. 5, no. 6, pp. 419-427, 2003.

[2] D. W. Shoesmith, J. J. Noël, and V. E. Annamalai, "3.10-corrosion of titanium and its alloys," in Reference Module in Materials Science and Materials Engineering-Shreir's Corrosion, vol. 3, pp. 2042-2052, 2010.

[3] Z. Ur Rahman, I. Shabib, and W. Haider, "Surface characterization and cytotoxicity analysis of plasma sprayed coatings on titanium alloys," Materials Science and Engineering: C, vol. 67, pp. 675-683, 2016.

[4] S. Podzimek, M. Tomka, T. Nemeth, L. Himmlova, P. Matucha, and J. Prochazkova, "Influence of metals on cytokines production in connection with successful implantation therapy in dentistry," Neuroendocrinology Letters, vol. 31, no. 5, pp. 657$662,2010$.

[5] Y. Luo and S. Ge, "Fretting wear behavior of nitrogen ion implanted titanium alloys in bovine serum lubrication," Tribology International, vol. 42, no. 9, pp. 1373-1379, 2009.

[6] G. B. de Souza, B. A. da Silva, G. Steudel, S. H. Gonsalves, C. E. Foerster, and C. M. Lepienski, "Structural and tribo-mechanical characterization of nitrogen plasma treated titanium for bone implants," Surface and Coatings Technology, vol. 256, pp. 30-36, 2014.

[7] J. Belohlavek, S. Belohlavkova, J. Hlubocky, V. Mrazek, A. Linhart, and S. Podzimek, "Severe allergic dermatitis after closure of foramen ovale with amplatzer occluder," Annals of Thoracic Surgery, vol. 96, no. 3, pp. e57-e59, 2013.

[8] S. A. Ahmad Kamal, R. Ritikos, and S. Abdul Rahman, "Wetting behaviour of carbon nitride nanostructures grown by plasma enhanced chemical vapour deposition technique," Applied Surface Science, vol. 328, pp. 146-153, 2015.

[9] G. Wang, H. Zhang, W. Li et al., "The preparation and evaluation of graded multilayer ta-C films deposited by FCVA method," Applied Surface Science, vol. 257, no. 11, pp. 5064-5069, 2011.

[10] B. Ifland, J. Hoffmann, T. Kramer, M. Scherff, S. Mildner, and C. Jooss, "Strain driven phase decomposition in ion-beam sputtered $\operatorname{Pr}_{1-X} \mathrm{Ca}_{X} \mathrm{MnO}_{3}$ films," Journal of Nanomaterials, vol. 2015, Article ID 935167, 12 pages, 2015.

[11] P. Vlcak and I. Jirka, "Protective sliding carbon-based nanolayers prepared by argon or nitrogen ion-beam assisted deposition on Ti6Al4V alloy," Journal of Nanomaterials, vol. 2016, Article ID 1697090, 9 pages, 2016.

[12] H. Schmidt, A. Schminke, M. Schmiedgen, and B. Baretzky, "Compound formation and abrasion resistance of ion-implanted Ti6Al4V," Acta Materialia, vol. 49, no. 3, pp. 487-495, 2001.

[13] C. Pierret, L. Maunoury, I. Monnet et al., "Friction and wear properties modification of Ti-6Al-4V alloy surfaces by implantation of multi-charged carbon ions," Wear, vol. 319, no. 1-2, pp. 19-26, 2014.

[14] A. Loinaz, M. Rinner, F. Alonso, J. I. Oñate, and W. Ensinger, "Effects of plasma immersion ion implantation of oxygen on mechanical properties and microstructure of Ti6A14V," Surface and Coatings Technology, vol. 103-104, pp. 262-267, 1998. 
[15] X. T. Zu, Y. Z. Liu, J. Lian et al., "Surface modification of a TiAl-Zr alloy by niobium ion implantation," Surface and Coatings Technology, vol. 201, no. 6, pp. 3756-3760, 2006.

[16] P. Vlcak, F. Cerny, J. Drahokoupil, J. Sepitka, and Z. Tolde, "The microstructure and surface hardness of Ti6Al4V alloy implanted with nitrogen ions at an elevated temperature," Journal of Alloys and Compounds, vol. 620, pp. 48-54, 2015.

[17] W. C. Oliver and G. M. Pharr, "Improved technique for determining hardness and elastic modulus using load and displacement sensing indentation experiments," Journal of Materials Research, vol. 7, no. 6, pp. 1564-1583, 1992.

[18] M. S. Oskooie, M. S. Motlagh, and H. Aghajani, "Surface properties and mechanism of corrosion resistance enhancement in a high temperature nitrogen ion implanted medical grade Ti," Surface and Coatings Technology, vol. 291, pp. 356-364, 2016.

[19] Y. V. Borisyuk, N. M. Oreshnikova, M. A. Berdnikova, A. V. Tumarkin, G. V. Khodachenko, and A. A. Pisarev, "Plasma nitriding of titanium alloy Ti5Al4V2Mo," Physics Procedia, vol. 71, pp. 105-109, 2015.

[20] D. Craciun, N. Stefan, G. Socol et al., "Very hard TiN thin films grown by pulsed laser deposition," Applied Surface Science, vol. 260, pp. 2-6, 2012.

[21] A. Wang, Ch. Chuang, G. Yu, and J. Huang, "Determination of average X-ray strain (AXS) on TiN hard coatings using $\cos ^{2} \alpha \sin ^{2} \psi$ X-ray diffraction method," Surface and Coatings Technology, vol. 262, pp. 40-47, 2015. 

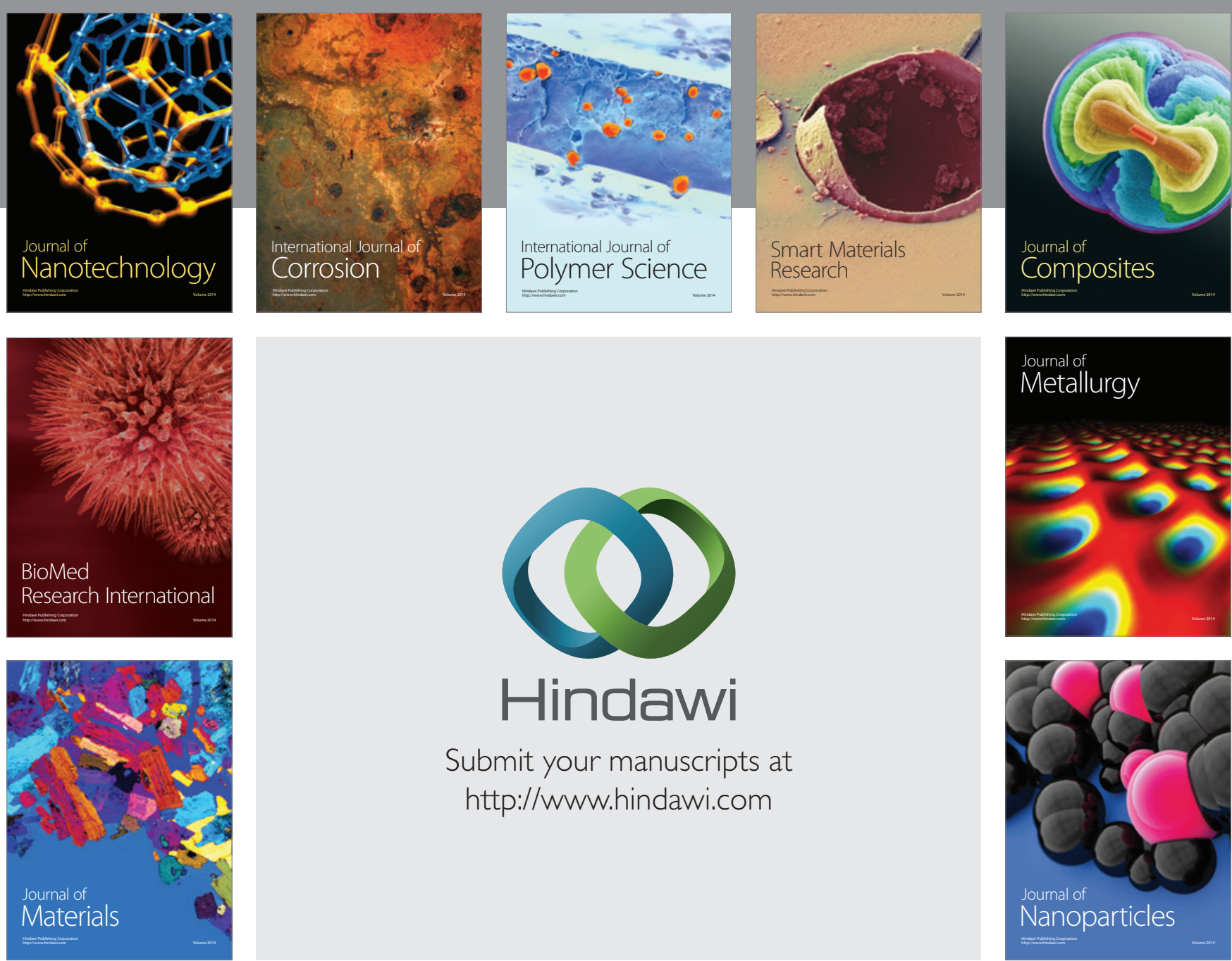

\section{Hindawi}

Submit your manuscripts at

http://www.hindawi.com

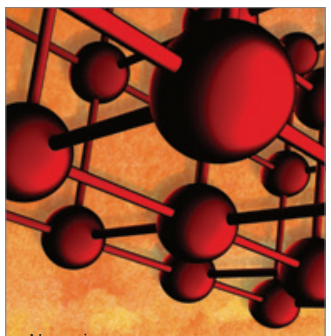

Materials Science and Engineering
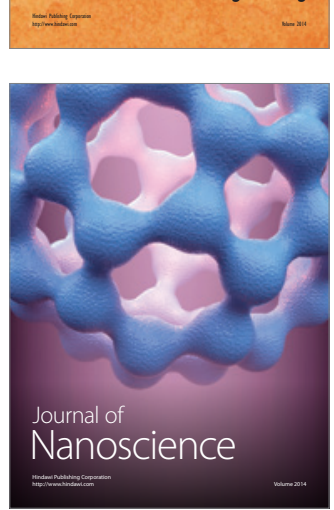
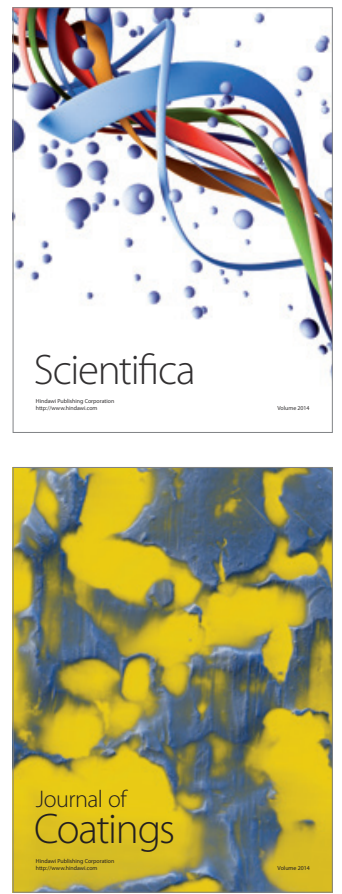
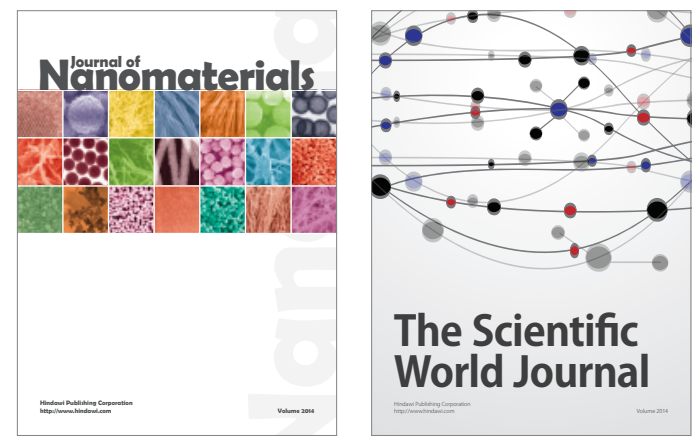

The Scientific World Journal
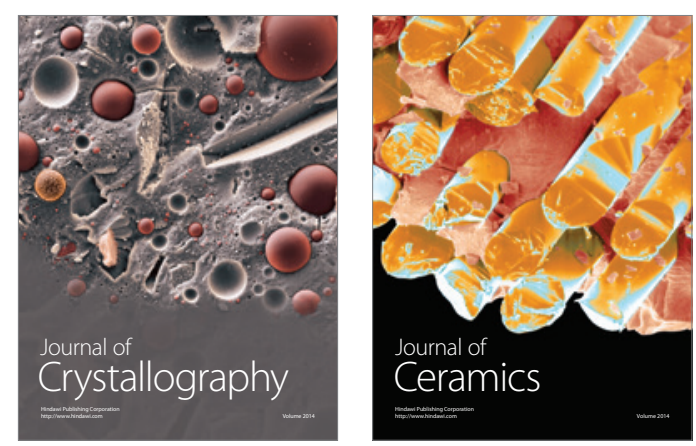
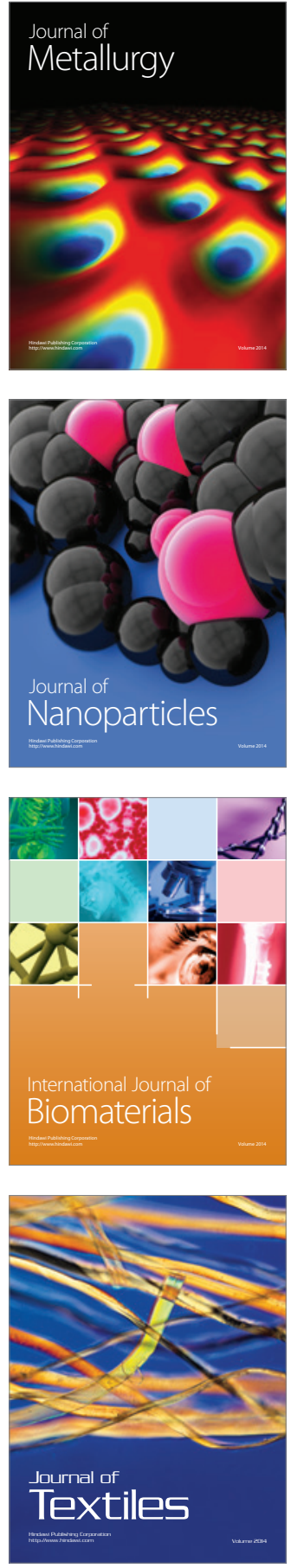